\title{
Non-high-density Lipoprotein Cholesterol Levels in Japanese Obese Boys with Metabolic Syndrome
}

\author{
Emiko Saito ${ }^{1}$, Tomoo Okada ${ }^{1,2}$, Yuriko Abe ${ }^{1}$, Minako Kazama ${ }^{1}$, Ryuta Yonezawa ${ }^{1}$, Yuki Kuromori ${ }^{1}$, \\ Fujihiko Iwata ${ }^{1}$ and Mitsuhiko Hara ${ }^{3}$
}

\begin{abstract}
${ }^{1}$ Department of Pediatrics and Child Health, Nihon University School of Medicine, Tokyo, Japan
${ }^{2}$ Department of Nutrition and Life Science, Kanagawa Institute of Technology, Kanagawa, Japan

${ }^{3}$ Department of Pediatrics, Tokyo Metropolitan Hiroo Hosipital, Tokyo, Japan
\end{abstract}

\begin{abstract}
Aim: To investigate the relationship between the clustering of metabolic syndrome (MetS) components and non-high-density lipoprotein cholesterol (non-HDL-C) levels in Japanese obese boys.

Methods: Subjects were 58 obese boys aged $12.0 \pm 2.6$ years, which were categorized into three subgroups: abdominal obesity, pre-MetS (abdominal obesity +1 component), and MetS (abdominal obesity +2 or more components).

Results: Sixteen (27.6\%) and $32(55.2 \%)$ of the obese boys were diagnosed as pre-MetS and MetS, respectively. The mean non-HDL-C level in total subjects was $139.0 \pm 36.4 \mathrm{mg} / \mathrm{dl}$ and that in boys with abdominal obesity, pre-MetS, and MetS were 112.9 $\pm 34.4,135.4 \pm 37.9$, and $149.0 \pm 32.6 \mathrm{mg} /$ $\mathrm{dl}$, respectively ( $p=0.0183$, ANOVA).

Conclusions: Japanese obese boys with MetS exhibited elevated non-HDL-C levels, suggesting that they may have a higher risk for the development of atherosclerotic diseases.
\end{abstract}

J Atheroscler Thromb, 2016; 23: 105-111.

Key words: Non-high-density lipoprotein cholesterol, Obese children, Metabolic syndrome

\section{Introduction}

Non-high-density lipoprotein cholesterol (nonHDL-C) includes all atherogenic apolipoprotein B (apoB)-containing lipoproteins, triglyceride (TG)-rich lipoproteins, cholesteryl ester-enriched remnants of TG-rich lipoproteins, and lipoprotein (a) ${ }^{1)}$. In addition, recent studies in adults have shown that nonHDL-C may be a better predictor for the development of atherosclerotic diseases than low-density lipoprotein cholesterol (LDL-C) ${ }^{2-4)}$. Thus, the Adult Treatment Panel III (ATP III) from the National Education Cholesterol Program (NCEP) recommended using LDL-C as a primary and non-HDL-C as a secondary therapeutic target for patients with TG levels

Address for correspondence: Tomoo Okada, Department of Pediatrics and Child Health, Nihon University School of Medicine, 30-1 Oyaguchi Kamicho, Itabashi-ku, Tokyo 1738610, Japan

E-mail: tomo@med.email.ne.jp

Received: April 3, 2015

Accepted for publication: August 8, 2015 $\geq 200 \mathrm{mg} / \mathrm{dL}^{5)}$. The Japan Atherosclerosis Society (JAS) guidelines for the diagnosis and prevention of atherosclerotic cardiovascular diseases 2012 also recommended the use of non-HDL-C levels as the secondary marker when a blood sample is collected without fasting or TG levels are $\geq 400 \mathrm{mg} / \mathrm{dl}^{6,7)}$.

Metabolic syndrome (MetS), a multiple risk factor clustering syndrome caused by visceral fat accumulation, is closely associated with the development of atherosclerosis ${ }^{8,9)}$. High TG and/or low HDL-C levels are the components of the diagnostic criteria of MetS ${ }^{10)}$. Recently, non-HDL-C levels in MetS have been investigated in several studies. Among US adults, persons with high non-HDL-C and normal LDL-C were almost 11 times more likely to have MetS than their counterparts with normal levels for each ${ }^{11)}$. In the case of children and adolescents, it has been suggested that non-HDL-C might serve as a simple and useful marker to identify individuals at a high risk of $\mathrm{Met} \mathrm{S}^{12)}$. In addition, the Bogalusa Heart Study demonstrated that non-HDL-C is as good as or better than other widely recommended lipoprotein measure- 
ments, including LDL-C, in the identification of increased carotid intima-media thickness, a validated measurement of subclinical atherosclerosis, in young adults aged 24 to 48 years ${ }^{13}$. Furthermore, the Pathobiological Determinants of Atherosclerosis in Youth (PDAY) study determined high non-HDL-C and low HDL-C as significant factors for the histological progression from fatty streak to advanced atherosclerotic lesions in subjects aged 15-34 years who died of external causes (accidents, homicides, or suicides) ${ }^{14)}$. Above findings suggest that non-HDL-C measurement is useful not only for detecting current MetS but also for evaluating the atherosclerotic risk in MetS subjects, even in younger age. In Japan, cross-sectional analysis showed that the prevalence of childhood obesity has gradually decreased since the early 2000s, with the highest prevalence in the late 1990 s to early $2000 \mathrm{~s}^{15)}$. However, the prevalence of MetS is not lower in preteen Japanese overweight children in comparison with overweight adolescents in United States ${ }^{16)}$. Therefore, the utility of using non-HDL-C may become more important in the management of children with MetS. However, few data are available about non-HDL-C levels in Japanese children and adolescents with MetS.

In this study of Japanese obese boys, we investigated the clustering of the components of MetS and its relationship with non-HDL-C levels.

\section{Subjects and Methods}

The study protocol was approved by the University Ethics Committee (Nihon University, Itabashi Hospital), and informed consent was obtained from each child and parents.

The study subjects were 58 obese boys aged $12.0 \pm 2.6$ years $($ mean $\pm \mathrm{SD})$ with a body mass index (BMI) of $28.9 \pm 5.3 \mathrm{~kg} / \mathrm{m}^{2}$ (BMI SD-score; $2.2 \pm 0.5$ ) who were recruited from the outpatient clinic in our institute. Obesity is defined as having a percentage of overweight $>20 \%$ calculated according to the standard weight for sex, age, and height: [(body weight standard weight)/standard weight $] \times 100^{17)}$. The waist circumference was measured at the level of the umbilicus and the waist to height ratio (WHtR) was calculated. Systolic blood pressure (SBP) and diastolic blood pressure (DBP) were measured in the right arm with subjects seating quietly. Blood samples were collected after overnight fasting. Total cholesterol (TC), HDL-C, and TG levels were measured by enzymatic methods. Non-HDL-C is defined as TC minus HDLC. ApoA-I, apoB, and apoE levels were measured by turbidimetric immunoassay (Daiichi Pure Chemicals,
Tokyo, Japan). Insulin and glucose levels were also determined and the homeostasis model of assessment ratio (HOMA-R) was obtained using Matthews' formula ${ }^{18)}$. Total serum adiponectin levels were measured by enzyme-linked immunosorbent assay.

In the present study, we employed the diagnostic criteria of MetS in Japanese children as having abdominal obesity (waist circumference $\geq 80 \mathrm{~cm}$ and/or WHtR $\geq 0.5$ ) plus two or more of the following: (i) dyslipidemia: high $\mathrm{TG} \geq 120 \mathrm{mg} / \mathrm{dl}$ and/or low HDL-C $<40 \mathrm{mg} / \mathrm{dl}$; (ii) elevated SBP $(\geq 125 \mathrm{mmHg})$ and/or DBP ( $\geq 70 \mathrm{mmHg}$ ); and (iii) elevated fasting glucose level $(\geq 100 \mathrm{mg} / \mathrm{dl})^{19)}$. In case of elementary school boys, the cutoff value of waist circumference is $75 \mathrm{~cm}$. Subjects with abdominal obesity plus one component were diagnosed as pre-MetS.

\section{Statistical Analyses}

All data were expressed as mean \pm SD. The correlation coefficients between the two variables were determined by single regression analysis. The differences in variables among three subgroups (abdominal obesity, pre-MetS, and MetS) were analyzed by oneway ANOVA with post-hoc test. A $P$-value less than 0.05 was considered to indicate statistical significance. All statistical analyses were conducted using the statistical package STATVIEW (v4.5; Abacus Concepts, Berkeley, CA, USA).

\section{Results}

\section{Characteristics of Subjects}

The characteristics of subjects are shown in Table 1. All boys in this study had abdominal obesity. We found 20 boys $(34.5 \%)$ with elevated SBP, 29 boys (50.0\%) with elevated DBP, and nine boys (15.5\%) with high fasting glucose levels. High TG and low HDL-C levels were demonstrated in $26(44.8 \%)$ and $12(20.7 \%)$ boys, respectively. Sixteen $(27.6 \%)$ and 32 $(55.2 \%)$ of the boys were diagnosed as pre-MetS and MetS, respectively. The mean non-HDL-C level in total boys was $139.0 \pm 36.4 \mathrm{mg} / \mathrm{dl}(73-225 \mathrm{mg} / \mathrm{dl})$.

\section{Relationship between Measured Variables and Non-HDL-C Level}

The non-HDL-C level had significant positive relationships with the TG $(r=0.576, p<0.0001)$ and LDL-C $(r=0.925, p<0.0001)$ level but not with WHtR $(r=0.091, p=0.4967)$, HDL-C level $(r=$ $-0.219, p=0.0986)$, SBP $(r=0.158, p=0.2405)$, DBP $(r=0.072, p=0.5940)$, or glucose level $(r=-0.112$, $p=0.4099)$. In addition, the non-HDL-C level significantly correlated with the apoB level $(r=0.977, p<$ 
Table 1. Characteristics of the subjects

\begin{tabular}{|c|c|c|c|c|c|}
\hline & $\begin{array}{l}\text { total } \\
n=58\end{array}$ & $\begin{array}{l}\text { abdominal obesity } \\
\qquad n=10\end{array}$ & $\begin{array}{c}\text { pre-MetS } \\
n=16\end{array}$ & $\begin{array}{l}\text { MetS } \\
n=32\end{array}$ & $p$ value \\
\hline Age (year) & $11.8 \pm 2.4$ & $10.4 \pm 2.1$ & $11.0 \pm 2.2$ & $12.6 \pm 2.3^{* \wedge}$ & 0.0091 \\
\hline Height $(\mathrm{cm})$ & $153.5 \pm 14.4$ & $144.4 \pm 10.4$ & $147.6 \pm 12.3$ & $159.6 \pm 13.9^{* \wedge}$ & 0.0014 \\
\hline Body weight (kg) & $70.1 \pm 23.3$ & $55.7 \pm 14.3$ & $62.2 \pm 20.0$ & $78.5 \pm 24.0^{* \wedge}$ & 0.0058 \\
\hline Waist circumference $(\mathrm{cm})$ & $93.0 \pm 13.0$ & $85.9 \pm 8.9$ & $90.5 \pm 13.7$ & $96.6 \pm 12.8^{*}$ & 0.0452 \\
\hline Percentage of overweight (\%) & $54.6 \pm 21.8$ & $47.9 \pm 15.1$ & $53.0 \pm 21.2$ & $57.4 \pm 23.8$ & 0.4645 \\
\hline Waist/height ratio & $0.60 \pm 0.06$ & $0.60 \pm 0.04$ & $0.61 \pm 0.07$ & $0.61 \pm 0.06$ & 0.8611 \\
\hline Total cholesterol (mg/dl) & $187.1 \pm 35.7$ & $169.5 \pm 31.2$ & $185.3 \pm 35.4$ & $193.5 \pm 36.2$ & 0.1746 \\
\hline LDL-cholesterol (mg/dl) & $113.7 \pm 30.1$ & $101.2 \pm 32.3$ & $114.6 \pm 29.8$ & $117.2 \pm 29.6$ & 0.3457 \\
\hline HDL-cholesterol (mg/dl) & $48.1 \pm 11.8$ & $56.6 \pm 8.8$ & $49.9 \pm 14.3$ & $44.5 \pm 9.8^{*}$ & 0.012 \\
\hline Triglyceride (mg/dl) & $120.1 \pm 70.0$ & $58.5 \pm 24.4$ & $99.4 \pm 63.3$ & $149.4 \pm 67.3^{* \wedge}$ & 0.0003 \\
\hline Non-HDL-cholesterol (mg/dl) & $139.0 \pm 36.4$ & $112.9 \pm 34.4$ & $135.4 \pm 37.9$ & $149.0 \pm 32.6^{*}$ & 0.0183 \\
\hline Apolipoprotein A-I (mg/dl) & $125.3 \pm 17.8$ & $124.6 \pm 17.6$ & $128.7 \pm 19.3$ & $123.5 \pm 17.5$ & 0.7358 \\
\hline Apolipoprotein A-II (mg/dl) & $31.1 \pm 5.3$ & $30.1 \pm 6.0$ & $31.1 \pm 3.9$ & $31.4 \pm 6.1$ & 0.8913 \\
\hline Apolipoprotein B (mg/dl) & $86.8 \pm 24.2$ & $75.8 \pm 31.1$ & $81.9 \pm 25.7$ & $92.5 \pm 21.3$ & 0.2775 \\
\hline Fasting glucose (mg/dl) & $93.3 \pm 6.6$ & $93.5 \pm 3.7$ & $90.9 \pm 5.4$ & $94.4 \pm 7.6$ & 0.2355 \\
\hline Insulin $(\mu \mathrm{U} / \mathrm{ml})$ & $17.8 \pm 14.0$ & $11.3 \pm 5.4$ & $12.9 \pm 10.4$ & $23.1 \pm 16.1$ & 0.0684 \\
\hline HOMA-R & $4.1 \pm 3.7$ & $2.5 \pm 1.3$ & $2.9 \pm 2.3$ & $5.4 \pm 4.4$ & 0.1237 \\
\hline Adiponectin $(\mu \mathrm{g} / \mathrm{ml})$ & $3.5 \pm 2.0$ & $5.3 \pm 2.6$ & $3.8 \pm 1.9$ & $2.3 \pm 0.9^{*}$ & 0.0086 \\
\hline Systolic blood pressure $(\mathrm{mmHg})$ & $118.7 \pm 14.5$ & $106.3 \pm 5.5$ & $111.3 \pm 10.0$ & $126.0 \pm 13.9^{* \wedge}$ & $<0.0001$ \\
\hline Diastolic blood pressure $(\mathrm{mmHg})$ & $69.9 \pm 9.9$ & $60.6 \pm 5.4$ & $63.5 \pm 8.6$ & $75.7 \pm 7.2$ & $<0.0001$ \\
\hline
\end{tabular}

mean $\pm S D$

ANOVA with host hoc test

$*: p<005$, abdominal obesity vs. MetS

$\wedge: p<0.05$, Pre-MetS vs. MetS

$0.0001)$, insulin level $(r=0.362, p=0.0324)$, HOMA$\mathrm{R}(p=0.419, p=0.0188)$, and adiponectin level $(r=$ $-0.486, p=0.0102)$ but not with the apoA-I $(r=0.077$, $p=0.6504)$ or apoA-II level $(r=0.319, p=0.0544)$.

\section{Impact of the Clustering of MetS Components on the Non-HDL-C Level}

Non-HDL-C levels in boys with abdominal obesity, pre-MetS, and MetS were 112.9 $\pm 34.4,135.4 \pm$ 37.9 , and $149.0 \pm 32.6 \mathrm{mg} / \mathrm{dl}$, respectively. The clustering of MetS components showed a significant association with non-HDL-C levels $(p=0.0183)$ (Fig. 1). Compared with subjects with abdominal obesity, nonHDL-C levels in those with MetS were significantly higher by post-hoc test $(p=0.0374)$.

\section{Discussion}

The present study demonstrated that boys with MetS had a significantly higher non-HDL-C level than those with only abdominal obesity. In addition, the non-HDL-C level in boys with pre-MetS showed an intermediate value. These results suggest that the clustering of MetS components is an important factor contributing to the elevation of non-HDL-C levels in Japanese obese boys.

Obesity, particularly abdominal obesity, has been accepted as a significant determinant of non-HDL-C levels in adults ${ }^{20,21)}$ and also in children ${ }^{22)}$. In the present study of obese boys, non-HDL-C levels had no association with WHtR. However, compared with the reference ranges of non-HDL-C levels in Japanese children $^{23)}$, boys with abdominal obesity had higher levels of non-HDL-C, even in those without other component of MetS. In addition, non-HDL-C levels were demonstrated to have strong associations with LDL-C and apoB levels. The Bogalusa Heart Study demonstrated that non-HDL-C is as good as or better than LDL-C in the identification of increased carotid intima-media thickness in young adults ${ }^{13)}$. Thus, the elevated non-HDL-C levels observed in this study may indicate an atherosclerotic risk in Japanese boys with abdominal obesity.

Recent study in apparent healthy adults demonstrated that the non-HDL-C level significantly correlated with each non-lipid component, such as fasting 


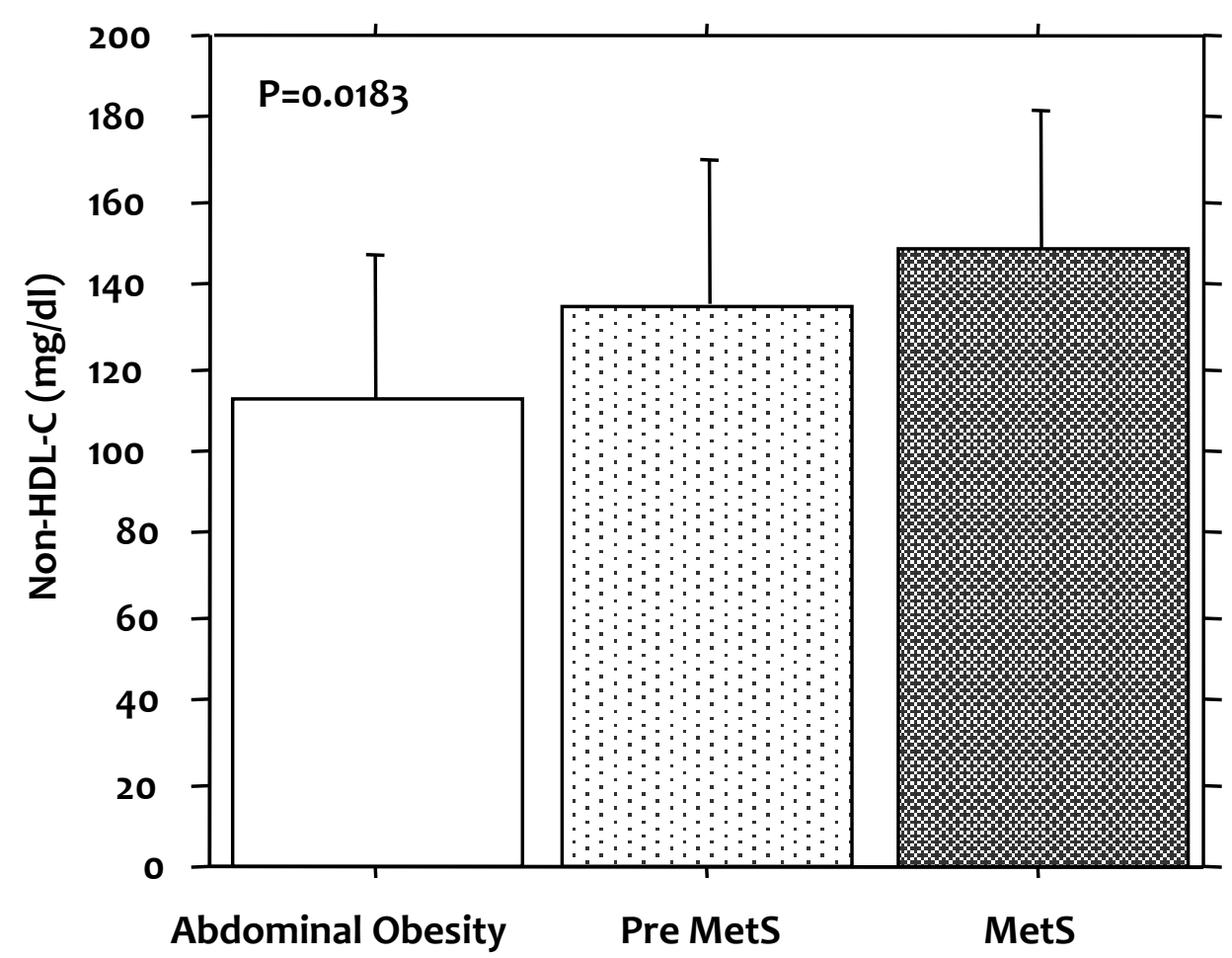

Fig. 1. Relationships between the clustering of MetS components and non-HDL-C levels.

glucose, SBP, and DBP as well as with TG and HDL-C levels ${ }^{24)}$. In the study of Canadian adolescents aged $12-19$ years, those who had impaired fasting glucose and high levels of non-HDL-C demonstrated to be more likely to have clustered MetS components ${ }^{25}$. Another study among US adolescents also demonstrated that non-HDL-C has a close relationship with the presence of multiple risk factors ${ }^{12)}$. In the present study, we found that the non-HDL-C level significantly correlated with the insulin level, HOMA-R, and adiponectin level. Therefore, non-HDL-C levels have an association with current insulin resistant state during childhood as well as with atherosclerotic risks. Insulin resistance is a key mechanism underlying MetS. In addition, Ley et al. investigated the incidence of type 2 diabetes during a 10 -year follow-up period and demonstrated that the cumulative incidence of type 2 diabetes was $17.5 \%$ and non-HDL-C at baseline, but not LDL-C or HDL-C, was a risk predictor of the incidence ${ }^{26)}$. Therefore, the elevated non-HDL$\mathrm{C}$ levels observed in MetS may predispose to the development of not only cardiovascular diseases but also type 2 diabetes.

Non-HDL-C has many greater benefits beyond LDL-C in pediatric clinical settings because nonHDL-C is easy to calculate and does not require fast- ing ${ }^{27)}$. The guidelines for cardiovascular health and risk reduction for children and adolescents in US recommends a universal screening with non-fasting nonHDL-C, and a non-HDL-C value of $\geq 145 \mathrm{mg} / \mathrm{dl}$ is used to identify a dyslipidemic state in children and adolescents up to 19 years of age ${ }^{28)}$. However, nonHDL-C levels in children and adolescents vary with age, sex, and race/ethnicity ${ }^{29)}$. Thus, it is important that own population reference values are used in the clinical practice to identify cardiovascular risk factors in pediatric age group ${ }^{30)}$. Recently, reference ranges for non-HDL-C levels in Japanese children and adolescents were reported ${ }^{23)}$. Compared with reference ranges, the mean levels of non-HDL-C in boys with abdominal obesity $(112.9 \mathrm{mg} / \mathrm{dl})$ and MetS $(149.0 \mathrm{mg} / \mathrm{dl})$ in the present study were approximately 75 and over 95 percentiles, respectively. A study among US youth aged 12-19 years proposed the use of non-HDL-C thresholds of $120 \mathrm{mg} / \mathrm{dl}$ and $145 \mathrm{mg} / \mathrm{dl}$ to indicate borderline and high MetS risk, respectively ${ }^{12)}$. When the value $(\geq 145 \mathrm{mg} / \mathrm{dl})$ was applied to the present study, the prevalence of MetS was $57.6 \%$ in obese boys with high non-HDL-C and that in obese boys with non-HDL-C $<145 \mathrm{mg} / \mathrm{dl}$ was $51.2 \%$. Further studies are needed to obtain the cutoff value of non-HDL-C levels in Japanese children both in boys and girls. 


\section{Conclusions}

Japanese obese boys with MetS exhibited elevated non-HDL-C levels, suggesting that they may have a higher risk for the development of atherosclerotic diseases. Thus, non-HDL-C levels may be an important indicator in monitoring cardiovascular risks among boys with the clustering of MetS components.

\section{Acknowledgments}

We would like to thank the patients and their parents for participating in the present study who recognized the aim of this study, i.e., early prevention of atherosclerosis.

\section{COI}

No financial assistance was received to support this study.

We have no conflicts of interest.

\section{References}

1) Miller M, Ginsberg HN, and Schaefer EJ: Relative atherogenicity and predictive value of non-high-density lipoprotein cholesterol for coronary heart disease. Am J Cardiol, 2008; 101: 1003-1008

2) Lehto $S$, Ronnemaa T, Haffner SM, Pyorala K, Kallio V, and Laakso M: Dyslipidemia and hyperglycemia predict coronary heart disease events in middle-aged patients with NIDDM. Diabetes, 1997; 46: 1354-1359

3) Pischon T, Girman CJ, Sacks FM, Rifai N, Stampfer MJ, and Rimm EB: Non-high-density lipoprotein cholesterol and apolipoprotein $\mathrm{B}$ in the prediction of coronary heart disease in men. Circulation 2005; 112: 3375-3383

4) Boekholdt SM, Arsenault BJ, Mora S, Pedersen TR, LaRosa JC, Nestel PJ, Simes RJ, Durrington P, Hitman GA, Welch KM, DeMicco DA, Zwinderman AH, Clearfield MB, Downs JR, Tonkin AM, Colhoun HM, Gotto AM Jr, Ridker PM, and Kastelein JJ: Association of LDL cholesterol, non-HDL cholesterol, and apolopoprotein B levels with risk of cardiovascular events among patients treated with statins: a meta-analysis. JAMA, 2012; 307: 1302-1309

5) Grundy SM, Cleeman JI, Merz CN, Brewer HB Jr, Clark LT, Hunninghake DB, Pasternak RC, Smith SC Jr, and Stone NJ: Coordinating Committee of the National Cholesterol Education Program: Implications of recent clinical trials for the National Cholesterol Education Program Adult Treatment Panel III guidelines. Arterioscler Thromb Vasc Biol, 2004; 24: e149-161

6) Teramoto T, Sasaki J, Ishibashi S, Birou S, Daida H, Dohi $S$, Egusa G, Hiro $T$, Hirobe $K$, Iida M, Kihara S, Kinoshita M, Maruyama C, Ohta T, Okamura T, Yamashita S, Yokode M, and Yokote K; Japan Atherosclerosis Society: Executive summary of the Japan Atheroscle- rosis Society (JAS) guidelines for the diagnosis and prevention of atherosclerotic cardiovascular diseases in Japan -2012 version. J Atheroscler Thromb, 2013; 20: 517-523

7) Teramoto T, Sasaki J, Ishibashi S, Birou S, Daida H, Dohi $S$, Egusa $G$, Hiro $T$, Hirobe $K$, Iida $M$, Kihara $S$, Kinoshita M, Maruyama C, Ohta T, Okamura T, Yamashita S, Yokode M, and Yokote K: Diagnostic criteria for dyslipidemia; Executive Summary of the Japan Atherosclerosis Society (JAS) Guidelines for the Diagnosis and Prevention of Atherosclerotic Cardiovascular Diseases in Japan - 2012 Version. J Atheroscler Thromb, 2013; 20: 655-660

8) Ohnuki T, Takahashi W, Ohnuki Y, Kawada S, and Takizawa S: Significance of the presence of metabolic syndrome in patients with asymptomatic arteriosclerosis affecting the aorta and the cerebral, extra-cranial carotid and coronary arteries. Intern Med, 2013; 52: 523-527

9) Matsuzawa $Y$, Funahashi T, and Nakamura T: The concept of metabolic syndrome: contribution of visceral fat accumulation and its molecular mechanism. J Atheroscler Thromb, 2011; 18: 629-639

10) Lorenzo C, Williams K, Hunt KJ, and Haffner SM: The National Cholesterol Education Program - Adult Treatment Panel III, International Diabetes Federation, and World Health Organization definitions of the metabolic syndrome as predictors of incident cardiovascular disease and diabetes. Diabetes Care, 2007; 30: 8-13

11) Kilgore M, Muntner P, Woolley JM, Sharma P, Bittner V, and Rosenson RS: Discordance between high non-HDL cholesterol and high LDL-cholesterol among US adults. J Clin Lipidol, 2014; 8: 86-93

12) Li C, Ford ES, McBride PE, Kwiterovich PO, McCrindle BW, and Gidding SS: Non-high-density lipoprotein cholesterol concentration is associated with the metabolic syndrome among US youth aged 12-19 years. J Pediatr, 2011; 158: 201-207

13) Frontini MG, Srinivasan SR, Xu JH, Tang R, Bond MG, and Berenson G: Utility of non-high-density lipoprotein cholesterol versus other lipoprotein measures in detecting subclinical atherosclerosis in young adults (The Bogalusa Heart Study). Am J Cardiol, 2007; 100: 64-68

14) Homma S, Troxclair DA, Zieske AW, Malcom GT, and Strong JP; Pathobiological Determinants of Atherosclerosis in Youth Research Group: Histological changes and risk factor associations in type 2 atherosclerotic lesions (fatty streaks) in young adults. Atherosclerosis, 2011; 219: 184-190

15) Yoshinaga M, Ichiki T, Tanaka Y, Hazeki D, Horigome H, Takahashi H, and Kashima K: Prevalence of childhood obesity from 1978 to 2007 in Japan. Pediatr Int, 2010; 52: 213-217

16) Yoshinaga M, Tanaka S, Shimago A, Sameshima K, Nishi J, Nomura Y, Kawano Y, Hashiguchi J, Ichiki T, and Shimizu S: Metabolic syndrome in overweight and obese Japanese children. Obes Res, 2005; 13: 1135-1140

17) Ikiuo K, Hashimoto R, Murata M: Discussion on the new physical fitness definition in School Health Program On the comparison between a new and a previous definition for the physical fitness of school aged children and the secular trend of the prevalence of obesity and thinness 
in them from 1980 to 2000 -. J Child Health, 2010; 69: 6-13 (in Japanese with English abstract)

18) Matthews DR, Hosker JP, Rudenski AS, Naylor BA, Treacher DF, and Turner RC: Homeostasis model assessment: insulin resistance and beta-cell function from fasting plasma glucose and insulin concentrations in man. Diabetologia, 1985; 28: 412-419

19) Abe Y, Kikuchi T, Nagasaki K, Hiura M, Tanaka Y, Ogawa Y, and Uchiyama M: Usefulness of GPT for diagnosis of metabolic syndrome in obese Japanese children. J Atheroscler Thromb, 2009; 16: 902-909

20) Bos G, Dekker JM, and Heine RJ; Hoom study: NonHDL cholesterol contributes to the "hypertriglyceridemic waist" as a cardiovascular risk factor: the Hoorn study. Diabetes Care 2004; 27: 283-284

21) Hertelyova Z, Salaj R, Chmelarova A, Dombrovsky P, Dvorakova MC, and Kruzliak P: The association between lipid parameters and obesity in university students. J Endocrinol Invest 2015 Jan 20. [Epub ahead of print]

22) Giuliano I, Freitas S, Coutinho M, Zunino J, Caramelli B, and Berenson G: Distribution of HDL-cholesterol and non-HDL-cholesterol in Brazilian children and adolescents--the Floripa study. Nutr Metab Cardiovasc Dis 2011; 21:33-38

23) Abe Y, Okada T, Sugiura R, Yamauchi K, and Murata M: Reference Ranges for the Non-High-Density Lipoprotein Cholesterol Levels in Japanese Children and Adolescents. J Atheroscler Thromb, 2015; 22: 669-675

24) Liu A, and Reaven GM: Is measurement of non-HDL cholesterol an effective way to identify the metabolic syndrome? Nutr Metab Cardiovasc Dis 2013; 23: 1122-1127

25) Liu J, Joshi D, and Sempos CT: Non-high-density-lipo- protein cholesterol and cardiovascular risk factors among adolescents with and without impaired fasting glucose. Appl Physiol Nutr Metab, 2009; 34: 136-142

26) Ley SH, Harris SB, Connelly PW, Mamakeesick M, Gittelsohn J, Wolever TM, Hegele RA, Zinman B, and Hanley AJ: Utility of non-high-density lipoprotein cholesterol in assessing incident type 2 diabetes risk. Diabetes Obes Metab, 2012; 14: 821-825

27) Ramjee V, Sperling LS, and Jacobson TA: Non-high-density lipoprotein cholesterol versus apolipoprotein B in cardiovascular risk stratification: do the math. J Am Coll Cardiol, 2011; 58: 457-463

28) Expert panel on Integrated Guidelines for Cardiovascular Health and Risk Reduction in Children and Adolescents: Expert Panel on Integrated Guidelines for Cardiovascular Health and Risk Reduction in Children and Adolescents: Summary report. Pediatrics, 2011; 128(Suppl5): s213256

29) Dai S, Yang Q, Yuan K, Loustalot F, Fang J, Daniels SR, and Hong Y: Non-high-density lipoprotein cholesterol: distribution and prevalence of high serum levels in children and adolescents: United States National Health and Nutrition Examination Surveys, 2005-2010. J Pediatr, 2014; 164: 247-253

30) De Henauw S, Michels N, Vyncke K, Hebestreit A, Russo P, Intemann T, Peplies J, Fraterman A, Eiben G, de Lorgeril M, Tornaritis M, Molnar D, Veidebaum T, Ahrens W, and Moreno LA; IDEFICS consortium: Blood lipids among young children in Europe: results from the European IDEFICS study. Int J Obes (Lond), 2014; 38 Suppl 2: $567-75$ 
Supplemental Table 1

\begin{tabular}{|c|c|c|c|c|c|c|}
\hline & \multirow{2}{*}{$\begin{array}{c}\text { abdominal obesity } \\
\text { normal HDLC } \\
n=10\end{array}$} & \multicolumn{2}{|c|}{ pre-MetS } & \multicolumn{2}{|c|}{ MetS } & \multirow[b]{2}{*}{$p$ value } \\
\hline & & $\begin{array}{c}\text { low HDLC } \\
n=4\end{array}$ & $\begin{array}{c}\text { normal HDLC } \\
n=12\end{array}$ & $\begin{array}{c}\text { low HDLC } \\
n=8\end{array}$ & $\begin{array}{c}\text { normal HDLC } \\
n=24\end{array}$ & \\
\hline Non-HDL-C (mg/dl) & $112.9 \pm 34.4$ & $121.3 \pm 27.6$ & $140.1 \pm 40.7$ & $135.3 \pm 35.1$ & $153.5 \pm 31.1 *$ & 0.0334 \\
\hline
\end{tabular}

ANOVA with host hoc test

*: $p<005$, abdominal obesity vs. MetS with normal HDLC 